\title{
The frequency and relationship of osteoporosis and vitamin $D$ deficiency in the female geriatric population in Central Anatolia
}

\author{
(1)Tekin Yıldırım \\ Yozgat Bozok University, Faculty of Medicine, Department of Internal Medicine, Yozgat, Turkey
}

Cite this article as:Yıldırım T. The frequency and relationship of osteoporosis and vitamin D deficiency in the female geriatric population in Central Anatolia. J Health Sci Med 2021; 4(2): 223-227.

\begin{abstract}
Aims: The frequency of osteoporosis increases with age and is an important cause of mortality and morbidity due to hip fractures. The aim of our study is to determine the frequency of osteoporosis and vitamin D deficiency in female geriatric population and to investigate the relationship of vertebral and femur bone mineral densities (BMD) with vitamin D level in this population.

Material and Method: The study included 457 women aged 65 years and older. Vertebra and femur bone mineral densities (BMD) and serum 25-hydroxy vitamin D3 (25 (OH) D3) levels were measured.

Results: The mean age was found to be $72.4 \pm 5.7$ years. The mean L1-L4 and Femur neck BMD values in the participants were $-2.74 \pm 0.77,-2.31 \pm 0.95$ respectively, and the rate of osteoporosis was $72.2 \%(n=330)$. There was no statistically significant difference between age groups in respect to frequency of osteaporosis $(p=0.58)$. Weak negative correlation was found between femur neck BMD value and age $(\mathrm{r}=-0.26, \mathrm{p}<0.001)$. Vitamin D level was $13.00 \pm 8.80 \mathrm{ng} / \mathrm{ml}$ and vitamin $\mathrm{D}$ deficiency was $87.4 \%$ $(\mathrm{n}=387)$. There was no statistically significant difference between age groups in respect to frequency of vitamin $\mathrm{D}$ deficiency $(\mathrm{p}=0.16)$. Similarly, no statistically significant relationship was found between osteoporosis and vitamin $\mathrm{D}$ deficiency $(\mathrm{p}=0.65)$.

Conclusion: This study suggested that geographic, cultural, and genetic factors are more important determinants in the development of osteoporosis.
\end{abstract}

Keywords: Bone mineral density, Central Anatolia, female geriatric population, vitamin D

\section{INTRODUCTION}

Osteoporosis is a disease characterized by a decrease in bone density and deterioration in bone microarchitecture, and it is the most common metabolic disease of bone (1). Senile osteoporosis (Type II osteoporosis) is the type of osteoporosis seen in both women and men, especially after the age of 70 . Although many factors play a role in the pathogenesis of senile osteoporosis, the most important and emphasized cause is vitamin D deficiency and secondary hyperparathyroidism resulting from it (2).

Vitamin D is a steroid hormone that is essential for normal calcium and bone metabolism. The source of vitamin D in the body is cholecalciferol synthesized on the skin with the effect of ultraviolet light and ergocalciferol taken with diet. The initial metabolism of vitamin D precursors occurs in the form of hydroxylation (25-hydroxy vitamin D3 [25 (OH)D3]) in the 25th position of the carbon atom in the structure of the precursors in the liver. It is then transformed into its active form (1,25-hydroxy vitamin D3 [1,25 (OH)D3]) by hydroxylation of the carbon atom in its first position in $25(\mathrm{OH}) \mathrm{D} 3$ in the kidney. This active form provides bone mineralization by increasing absorption of calcium and phosphorus from the intestines (3).

The best indicator of vitamin $\mathrm{D}$ status in tissues is serum $25(\mathrm{OH}) \mathrm{D} 3$ level. Vitamin D deficiency is defined as the level of vitamin D at which histological, laboratory and clinical findings occur. Different threshold values are used for vitamin D deficiency $(4,5)$. Vitamin D deficiency is especially common in closed clothing societies, northern European countries, the elderly, and those living in nursing homes. The frequency of vitamin $\mathrm{D}$ deficiency increases in the elderly due to the decrease in ultraviolet light exposure, decreased skin's vitamin D synthesis capacity, inadequate intake of vitamin D with nutrients, increased renal dysfunction and malabsorption with aging (6). 
When there is a deficiency of Vitamin D, 1,25(OH)D3 level decreases, in response, the level of parathormone (PTH) increases. Increasing PTH level increases at 1,25 (OH) D3 level and causes bone destruction. Thus, a sufficient level of $1,25(\mathrm{OH}) \mathrm{D} 3$ is achieved despite increased bone destruction. This condition is called secondary hyperparathyroidism (7).

The aim of our study is to determine the frequency of vitamin $\mathrm{D}$ deficiency, which is one of the most important factors contributing to osteoporosis and senile osteoporosis in the female geriatric age group in Central Anatolia; to reveal the relationship between BMD values and osteoporosis and vitamin $\mathrm{D}$ deficiency in this population.

\section{MATERIAL AND METHOD}

Ethics committee approval was provided from the Yozgat Bozok University Medical Faculty Local Ethics Committee (approval no: 2017-KAEK-189_2019.02.28-21), and informed consent of each patient was obtained for the study. All procedures were performed adhered to the ethical rules and the Helsinki Declaration of Principles.

This prospective, cross-sectional study was conducted between March 1, 2019, and March 1, 2020 at the outpatient clinics of the internal medicine department in a tertiary hospital. The study consecutively included 457 women aged 65 years and older, who were admitted to the outpatient unit of Internal Medicine Department in the tertiary hospital, living in the community and independently acting in her daily life activities. The exclusion criteria were as follows: those who had renal failure (glomerular filtration rate less than $90 \mathrm{ml} / \mathrm{min}$ ), liver failure (liver transaminases levels more than two times of upper range of the limit), patients with secondary osteoporosis disease, patients with metabolic bone disease other than osteoporosis, bedridden patients, patient using drugs that may affect bone metabolism (thyroid hormones, estrogen, selective estrogen receptors, glucocorticoids, bisphosphonates, calcium, vitamin $\mathrm{D}+$ calcium). The individuals participating in the study were divided into three groups as per age: $65-74$ years old; 75-84 years old; and 85 years and older.

\section{BMD Measurement and Diagnosis of Osteoporosis}

Bone mineral densities (BMD) values were measured by using DEXA device (Discovery DXA, Hologic, Marlborough, Massachusetts, USA). The diagnosis of osteoporosis was made according to the World Health Organization (WHO) criteria for osteoporosis. Patients were divided into three groups according to the $\mathrm{T}$ score: Those with $\mathrm{T}$ score $>-1$ were normal, those with $-1 \geq \mathrm{T}$ score $>-2.5$ were considered osteopenic and those with $\mathrm{T}$ score $\leq-2.5$ were considered osteoporosis.

\section{Diagnosis of Vitamin D Deficiency}

$25(\mathrm{OH})$ D3 level was measured by radioimmunassay method (Diasorid, 25-Hydroxyvitamin D 125I RIA Kit, Stillwater, Minnesota, USA). Vitamin D levels were divided into 4 groups: $\geq 30 \mathrm{ng} / \mathrm{ml}$ was considered as sufficient Vitamin D level; $\geq 20 \mathrm{ng} / \mathrm{ml}$ but $<30 \mathrm{ng} / \mathrm{ml}$ as insufficient Vitamin D level; $\geq 10 \mathrm{ng} / \mathrm{ml}$ but $<20 \mathrm{ng} / \mathrm{ml}$ as deficient Vitamin D level; $<10 \mathrm{ng} / \mathrm{ml}$ level as osteomalasic. All individuals with values below $20 \mathrm{ng} / \mathrm{ml}$ were also considered as vitamin $\mathrm{D}$ deficiency.

\section{Statistical Analysis}

SPSS version 20.0 (Statistical Package for Social Sciences) program was used for statistical analysis of the findings. Descriptive statistics were used in the analysis of the data. Continuous variables are expressed as mean \pm standard deviation (SD) and nominal variables as percentage. Pearson's correlation test was used to evaluate the correlation between variables. Chi-square test was used to evaluate the significance of the differences between the groups. $\mathrm{P}$ value $<0.05$ was considered statistically significant.

\section{RESULTS}

The study included 457 women aged 65 years and older consecutively. The ages of the patients ranged from 65 to 95 years old, and the mean age of the study population was found to be $72.4 \pm 5.7$ years.

The mean values of L1-L4 and femur neck BMD were $-2.74 \pm 0.77$ and $-2.31 \pm 0.95$, respectively. Osteoporosis rate was $72.2 \%(n=330)$ among the study population. In terms of osteoporosis, the distribution of individuals was given in Table 1.

As per age groups, it was found that there was no statistically significant difference between age groups in respect to osteoporosis $(\mathrm{p}=0.58)$. Distribution of osteoporosis by age groups was shown in Table 2.

The average vitamin D level was $13.00 \pm 8.80 \mathrm{ng} / \mathrm{ml}$. Rate of vitamin D deficiency was found to be $87.4 \%(n=387)$. Frequency of vitamin D deficiency at the osteomalasic level was found to be $46.8 \%$. The distribution of individuals in terms of vitamin D deficiency was given in Table 3.

Considering the distribution of vitamin $\mathrm{D}$ deficiency according to age groups, there was no statistically significant difference between age groups $(\mathrm{p}=0.16)$. Distribution of vitamin D deficiency by age groups was shown in Table 4 .

When looking at the relationship between osteoporosis and vitamin $\mathrm{D}$ deficiency, no statistically significant relation was found $(\mathrm{p}=0.65)$. When looking at the relationship between osteoporosis and vitamin $\mathrm{D}$ deficiency at osteomalasic level, there was no statistically significant relation $(\mathrm{p}=0.18)$. The relation between osteoporosis and vitamin D deficiency was expressed in Table 5. 


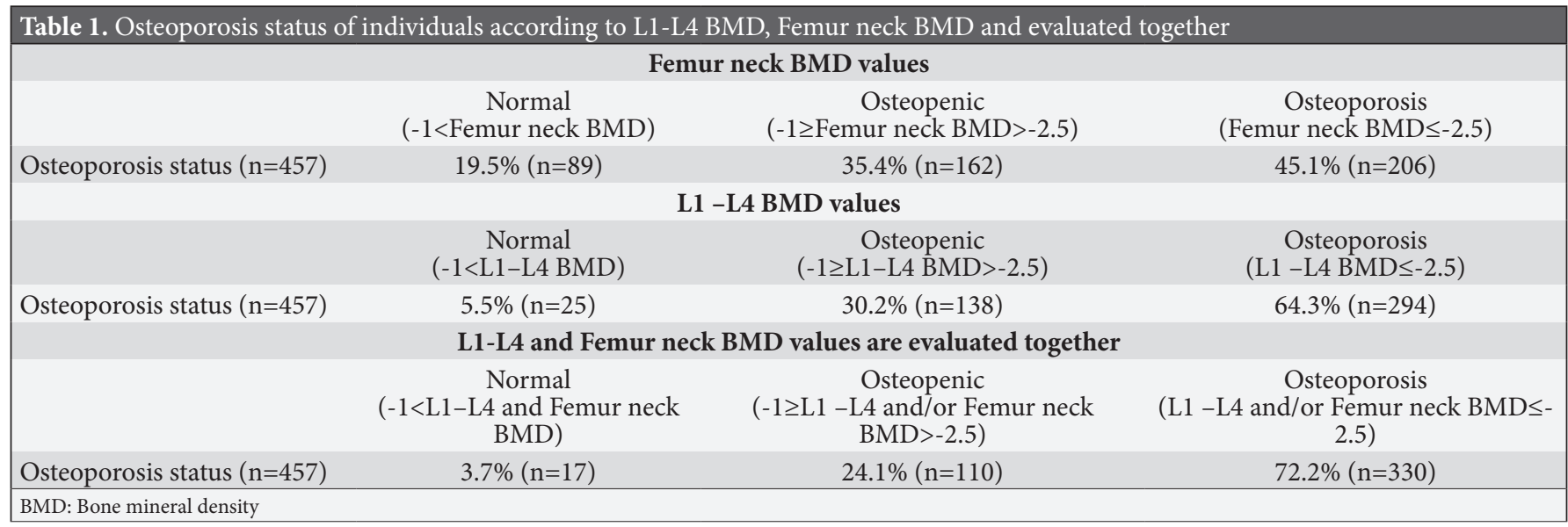

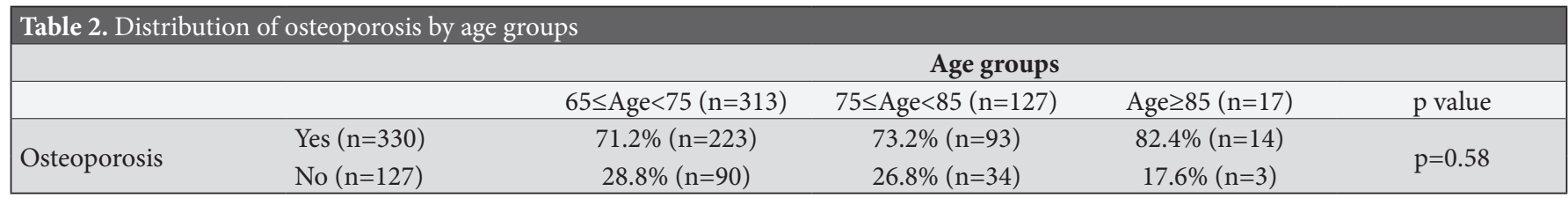

\section{Table 3. Distribution of individuals according to $25(\mathrm{OH})$ D3 levels}

\begin{tabular}{|lcccc|}
\hline & \multicolumn{4}{c|}{$\mathbf{2 5}(\mathbf{O H}) \mathbf{D} 3$ levels $(\mathbf{n g} / \mathbf{m l})$} \\
\hline & Osteomalasic & Deficient & Insufficient & Sufficient \\
& $(25(\mathrm{OH}) \mathrm{D} 3<10)$ & $(10 \leq 25(\mathrm{OH}) \mathrm{D} 3<20)$ & $(20 \leq 25(\mathrm{OH}) \mathrm{D} 3<30)$ & $(25(\mathrm{OH}) \mathrm{D} 3 \geq 30)$ \\
Vitamin D status $(\mathrm{n}=457)$ & $46.8 \%(\mathrm{n}=214)$ & $37.9 \%(\mathrm{n}=173)$ & $9 \%(\mathrm{n}=41)$ & $6.3 \%(\mathrm{n}=29)$ \\
\hline 25(OH) D3: 25-hydroxy vitamin D3 & & & & \\
\hline
\end{tabular}

\begin{tabular}{|c|c|c|c|c|c|}
\hline & \multicolumn{5}{|c|}{ Age groups } \\
\hline & & $65 \leq$ Age $<75(n=313)$ & $75 \leq$ Age $<85(n=127)$ & Age $\geq 85(n=17)$ & $\mathrm{p}$ value \\
\hline \multirow{2}{*}{$\begin{array}{l}\text { Vitamin D deficiencyi } \\
(<20 \mathrm{ng} / \mathrm{ml})\end{array}$} & Yes $(n=387)$ & $85 \%(n=266)$ & $81.9 \%(n=104)$ & $100 \%(n=17)$ & \multirow[b]{2}{*}{$\mathrm{p}=0.16$} \\
\hline & No $(n=127)$ & $15 \%(n=47)$ & $18.1 \%(n=23)$ & $0 \%(n=0)$ & \\
\hline
\end{tabular}

\begin{tabular}{|c|c|c|c|c|}
\hline & \multicolumn{4}{|c|}{ Vitamin D deficiency at osteomalasic levals $(25(\mathrm{OH}) \mathrm{D} 3$ levels $<10 \mathrm{ng} / \mathrm{ml})$} \\
\hline & & Yes $(n=214)$ & No $(n=243)$ & p value \\
\hline \multirow{4}{*}{$\begin{array}{l}\text { Osteoporosis (L1 -L4 and/or } \\
\text { Femur neck BMD } \leq-2.5 \text { ) }\end{array}$} & Yes $(n=330)$ & $48.8 \%(n=161)$ & $51.2 \%(n=169)$ & \multirow{2}{*}{$\mathrm{p}=0.18$} \\
\hline & No $(n=127)$ & $41.7 \%(n=53)$ & $58.3 \%(n=74)$ & \\
\hline & \multicolumn{4}{|c|}{ Vitamin D deficiency $(25(\mathrm{OH}) \mathrm{D} 3$ levels $<20 \mathrm{ng} / \mathrm{ml})$} \\
\hline & & Yes $(n=387)$ & No $(n=70)$ & p value \\
\hline \multirow{2}{*}{$\begin{array}{l}\text { Osteoporosis (L1 }-\mathrm{L} 4 \text { and/or } \\
\text { Femur neck BMD } \leq-2.5 \text { ) }\end{array}$} & Yes $(\mathrm{n}=330)$ & $85.2 \%(\mathrm{n}=281)$ & $14.8 \%(n=49)$ & \multirow{2}{*}{$\mathrm{p}=0.65$} \\
\hline & No $(n=127)$ & $83.5 \%(n=106)$ & $16.5 \%(n=21)$ & \\
\hline
\end{tabular}

In correlation analysis of vitamin D level and age, there was no statistically significant correlation between the two variables $(\mathrm{r}=-0.027, \mathrm{p}=0.56)$. In correlation analysis of L1-L4 with femoral neck BMD values and with vitamin $D$, there was no statistically significant correlation in both analyses $(\mathrm{r}=0.064, \mathrm{p}=0.17 ; \mathrm{r}=0.042$, $\mathrm{p}=0.37$, respectively). Similarly, there was no statistically significant correlation between L1-L4 BMD value and age $(\mathrm{r}=-0.091, \mathrm{p}=0.052)$. However, statistically significant but weak negative correlation was found between femoral neck BMD and age $(\mathrm{r}=-0.26, \mathrm{p}<0.001)$.

\section{DISCUSSION}

In our study, we evaluated vitamin $\mathrm{D}$ deficiency and frequency of osteoporosis in women aged 65 and older who applied to the internal medicine outpatient clinic. We found that $87.4 \%$ of the study population was found to have vitamin D deficiency. In the multi-centered "Survey in Europe on Nutrition and the Elderly; A Concerted Action" (SENECA) study that included individuals between the ages of 71-76 in European countries, 47\% of female participants and $36 \%$ of male participants were found to have Vitamin D deficiency. In this study, the level for vitamin D deficiency was accepted as $<12 \mathrm{ng} /$ 
ml. Interestingly, in the results of the study, the prevalence of vitamin D deficiency was found to be $83 \%$ in Greece among Mediterranean countries, while this rate was found to be $18 \%$ in Norway among Northern European countries (8). In a study conducted in the United States with the participation of 13,432 people, the rate of vitamin $\mathrm{D}$ deficiency $(<23.3 \mathrm{ng} / \mathrm{ml})$ was found to be $32 \%$ in individuals over 50 (9). In a study conducted by Hirani et al. (10) in individuals aged 65 and older in the UK, the rate of vitamin $\mathrm{D}$ deficiency $(10 \mathrm{ng} / \mathrm{ml})$ was found to be $15 \%$ in males and $9.6 \%$ in females. The prevalence of total vitamin D deficiency $(<15 \mathrm{ng} / \mathrm{ml})$ was found to be $33.4 \%$ in the study, which included 195 elderly people living at home and 225 elderly people living in the elderly nursing home. This rate was found to be $24.4 \%$ in the elderly living in their own homes and $40.1 \%$ in the elderly living in the nursing home (11). The frequency of vitamin D deficiency is higher in the elderly living in nursing homes compared to the elderly living in the community $(10,11)$. The prevalence of vitamin $\mathrm{D}$ deficiency varies depending on the geographic region, population, $25(\mathrm{OH}) \mathrm{D} 3$ threshold used for definition of vitamin $\mathrm{D}$ deficiency and dietary habits, but it is common in the geriatric population. The prevalence of vitamin $\mathrm{D}$ deficiency in the female elderly in our study was found to be higher than the elderly population described in the litareture. The reason for our higher rates may be because of religious beliefs that women are over-covered with clothing and the skin is less exposed to sunlight. Additionally, considering the fact that vitamin D deficiency was $83 \%$ in Greece in the SENECA study was close to the rate in our study, it suggests that geographic or especially genetic factors may be more important determinants in vitamin $\mathrm{D}$ deficiency and osteoporosis.

Osteoporosis is one of the most important causes of mortality and morbidity in this age group due to its frequency of up to $50 \%$ in the geriatric age group and increased risk of hip fracture. Although the prevalence of osteoporosis in women is higher than men in the postmenopausal period, the rate of osteoporosis detected in male gender after 65 years old approaches to that of female gender (12). In our study, the rate of osteoporosis was found to be $72.2 \%$ in women over 65 years old. It may be due to the fact that over-covering of women with clothes due to religious beliefs reduces the skin's exposure to sunlight. As a result, it may be that in women, bone mineralization has not reached the optimal level in the premenopausal period and the loss is faster and higher in the postmenopausal period. It also suggests that geographic or especially genetic factors may be more important determining factors.

Vitamin D deficiency is the most important cause of type II osteoporosis in the geriatric age group. Increased PTH levels cause increased bone production and destruction and decreased BMD. Secondary hyperparathyroidism, which develops due to vitamin D deficiency in the elderly, leads to a decrease in BMD and increase in fractures, especially in the hip region where the cortical bone is dense (13). In the Supplements en Vitamines et Mineraux Antioxydants (SUVIMAX) study conducted in France, a significant correlation was found between serum PTH and $25(\mathrm{OH}) \mathrm{D} 3$ levels. In this study, in patients with vitamin $\mathrm{D}$ deficiency but without secondary hyperparathyroidism, the decrease in BMD values was found to be less than in cases with secondary hyperparathyroidism. This situation has been associated with insufficient elevation of PTH level and inadequate bone resorption in some of the patients with vitamin $\mathrm{D}$ deficiency (14). In a study by Sahota et al. (15), a negative correlation was found between vitamin $\mathrm{D}$ and PTH values in 421 postmenopausal women aged 60 to 80 years old. Similar to the SUVIMAX study, insufficient PTH response was observed in some cases with vitamin $\mathrm{D}$ deficiency. The reason for the lack of a significant relationship between vitamin $\mathrm{D}$ deficiency and osteoporosis in our study may be due to that insufficient PTH response or serum $25(\mathrm{OH})$ D3 levels throughout the year in our study population.

In many studies conducted in the literature, while a relation was found between vitamin D deficiency and hip BMD values, the same relationship could not be revealed clearly with vertebral BMD values. The probable reason for not correlating with vertebral BMD values may be related with the increasing frequency of degenerative vertebral changes with increasing age, osteophytes and facet joint osteoarthritis frequently seen in lumbar vertebrae, and these degenerative changes appear as increased BMD values in DEXA measurements. In addition, due to the higher PTH activity in the cortical bone, the decrease in BMD is less in the vertebral bones where trabecular bone density is higher (16). In our study, no correlation was found between serum $25(\mathrm{OH}) \mathrm{D} 3$ levels and BMD values of the femoral neck and vertebrae. In the study conducted by Sahota et al. (15), total hip BMD values were lower in women with vitamin $\mathrm{D}$ deficiency and secondary hyperparathyroidism and a correlation was found between serum PTH and hip BMD values. However, the similar relationship was not determined for lumbal vertebra BMD value. Similarly, in another study, a negative correlation was found between serum $D$ vitamin level and PTH levels in 119 patients aged 65 - 90 years. There was a significant decrease in total hip BMD values in the group with vitamin $\mathrm{D}$ deficiency. However, lumbal vertebra BMD values were not found to have the same relationship (17). Contrary to the literature, in our study, the relationship between femur BMD values and serum $25(\mathrm{OH}) \mathrm{D} 3$ levels may be due to the fact that the vitamin $\mathrm{D}$ levels of the participants were measured throughout the year. It is likely that the values observed in spring 
and summer were higher and lower in winter. If all the participants' vitamin D levels in our study were examined in the same month, we would probably have shown the relationship more accurately. Perhaps geographic or genetic factors may be more important determinants of osteoporosis than vitamin D level.

Our study has several limitations. The first is that the study is cross-sectional. Causality cannot be evaluated in cross-sectional studies. The second limitation was that serum $25(\mathrm{OH}) \mathrm{D} 3$ levels was not measured at the same season of the year.

\section{CONCLUSION}

Serum vitamin D deficiency and osteoporosis are frequently seen in people aged 65 and over who apply to the outpatient clinic. Increasing exposure to sunlight and enriching frequently consumed foods with calcium and vitamin $\mathrm{D}$ can be simple but effective methods for increasing vitamin $\mathrm{D}$ levels in the elderly. However, this study suggests that cultural, geographical, and genetic factors may be more important determinants in the development of osteoporosis. Especially in the premenopausal period in which bone mineralization has reached the maximum level, in the societies where the exposure of the skin to the sunlight is insufficient excessive covering with clothes due to religious beliefs - calcium and vitamin D replacement may be decreased osteoporosis and fracture development at the geriatric age in these women. In other words, premenopausal calcium and vitamin $\mathrm{D}$ replacement may be more important than postmenopausal calcium and vitamin $\mathrm{D}$ replacement in these women.

\section{ETHICAL DECLARATIONS}

Ethics Committee Approval: The study was approved by the Yozgat Bozok University Medical Faculty Local Ethics Committee (approval no: 2017-KAEK-189_2019.02.2821).

Informed Consent: Written informed consent was obtained from all participants who participated in this study.

Referee Evaluation Process: Externally peer-reviewed.

Conflict of Interest Statement: Tekin Yıldırım declare that they have no conflict of interest.

Financial Disclosure: The authors declared that this study has received no financial support.

Author Contributions: All of the authors declare that they have all participated in the design, execution, and analysis of the paper, and that they have approved the final version.

\section{REFERENCES}

1. NIH Consensus Development Panel on Osteoporosis Prevention, Diagnosis, and Therapy, March 7-29, 2000: highlights of the conference. South Med J 2001; 94: 569-73.

2. Duque G, Demontiero O, Troen BR. Prevention and treatment of senile osteoporosis and hip fractures. Minerva Med 2009; 100: 79-94.

3. Bouillon R, Carmeliet G, Daci E, Segaert S, Verstuyf A. Vitamin D metabolism and action. Osteoporos Int 1998; 8: 13-9.

4. Holick MF. Vitamin D deficiency. N Engl J M 2007; 357: 266-81.

5. Akesson $\mathrm{K}$, Lau KH, Baylink DJ. Rationale for active vitamin D analog therapy in senile osteoporosis. Calcif Tissue Int 1997; 60: 100-5.

6. Girgis CM. Vitamin D and muscle function in the elderly: the elixir of youth? Curr Opin Clin Nutr Metab Care 2014; 17: 546-50.

7. Lupsa BC, Insogna K. Bone Health and Osteoporosis. Endocrinology and metabolism clinics of North America 2015; 44: 517-30.

8. van der Wielen RP, Lowik MR, van den Berg H, et al. Serum vitamin D concentrations among elderly people in Europe. Lancet 1995; 346: 207-10.

9. Bischoff-Ferrari HA, Dietrich T, Orav EJ, Dawson-Hughes B. Positive association between 25-hydroxy vitamin $\mathrm{D}$ levels and bone mineral density: a population-based study of younger and older adults. Am J Med 2004; 116: 634-9.

10. Hirani V, Primatesta P. Vitamin D concentrations among people aged 65 years and over living in private households and institutions in England: population survey. Age Ageing 2005; 34: 485-91.

11. Atli T, Gullu S, Uysal AR, Erdogan G. The prevalence of vitamin $\mathrm{D}$ deficiency and effects of ultraviolet light on vitamin $\mathrm{D}$ levels in elderly Turkish population. Arch Gerontol Geriatr 2005; 40: 53 60.

12. Olszynski WP, Shawn Davison K, Adachi JD, et al. Osteoporosis in men: epidemiology, diagnosis, prevention, and treatment. Clin Ther 2004; 26: 15-28.

13. Yendt ER, Kovacs KA, Jones G. Secondary hyperparathyroidism in primary osteoporosis and osteopenia: optimizing calcium and vitamin $\mathrm{D}$ intakes to levels recommended by expert panels may not be sufficient for correction. Clin Endocrinol 2008; 69: 855-63.

14. Chapuy MC, Preziosi P, Maamer M, al. Prevalence of vitamin D insufficiency in an adult normal population. Osteoporos Int 1997; 7: 439-43.

15. Sahota O, Mundey MK, San P, et al. The relationship between vitamin $\mathrm{D}$ and parathyroid hormone: calcium homeostasis, bone turnover, and bone mineral density in postmenopausal women with established osteoporosis. Bone 2004; 35: 312-9.

16. Allain TJ, Dhesi J. Hypovitaminosis D in older adults. Gerontol 2003; 49: 273-8.

17. Sahota O, Masud T, San P, Hosking DJ. Vitamin D insufficiency increases bone turnover markers and enhances bone loss at the hip in patients with established vertebral osteoporosis. Clin Endocrinol 1999; 51: 217-21. 